\title{
The effect of zeolite on oxidant/antioxidant status in healthy dairy cows
}

\author{
Hudai Ipek ${ }^{1}$, Mehmet Avci², Nurettin Aydilek ${ }^{1}$, Muğdat Yerturk ${ }^{3}$ \\ ${ }^{1}$ Department of Physiology, ${ }^{2}$ Department of Animal Nutrition, \\ ${ }^{3}$ Department of Animal Science, Faculty of Veterinary Medicine, University of Harran, Turkey
}

Received March 17, 2011

Accepted February 14, 2012

\begin{abstract}
This study was conducted to evaluate the effect of dietary zeolite (clinoptilolite) supplementation on the oxidative/antioxidative status on plasma in healthy dairy cows. Twenty dairy cows were divided into two groups of 10 . Control group was fed the basal ration for 60 days. Zeolite group was fed the basal ration supplemented with $2.5 \%$ zeolite daily. To evaluate the oxidative and antioxidative status comprehensively, indicators such as total oxidant status, oxidative stress index, total antioxidant status, lipid hydroperoxide, total free sulphhydryl groups, ceruloplasmin concentrations, arylesterase, paraoxonase-1 and catalase activities were measured in plasma. Lipid hydroperoxide concentration was significantly $(P<0.05)$ decreased from 6.21 \pm 0.94 to $4.90 \pm 1.05 \mathrm{mmol} \mathrm{H} \mathrm{O}_{2} \mathrm{Eq} / \mathrm{l}$ by zeolite supplementation. However, no significant effect was observed on the antioxidant and other oxidant indicators. In conclusion, although zeolite decreased the lipid hydroperoxide concentration, it cannot further strengthen antioxidant defense system in healthy dairy cows.
\end{abstract}

Clinoptilolite, oxidative stress, lipid hydroperoxide, total antioxidant status, dairy cattle

There are many stress factors impairing the health condition and performance of dairy cows. A common denominator of the responses to these stresses is the redox homeostasis. Redox homeostasis is maintained by the balance between production of reactive oxygen species (ROS) and antioxidant defense system. However, the level of ROS can exceed the antioxidant status of the animal leading to oxidative stress (Celli 2010). High producing dairy cows are prone to oxidative stress, and the situation can be exacerbated under certain environmental, physiological, and dietary conditions (Vazques-Anon et al. 2008).

Specific feeding strategies influence oxidative metabolism in the dairy cow. Dietary supplementation of some minerals for dairy cow's nutrition is important for the oxidative/ antioxidant balance of the animals and directly impacts on the productive and reproductive performance of animals (Vazques-Anon et al. 2008).

In the last few decades, natural zeolite (clinoptilolite), as an additive to nutrition has been applied with success in animal breeding for many purposes. Long-term dietary administration of zeolite has beneficial effects on animal health status and performance (Karatzia et al. 2011). The wide range of applications of zeolites is based on their physicochemical properties. Interest in the biological effects of zeolites stems from their characteristics such as ion exchange capacity, adsorption and related molecular sieve properties (Pavelic et al. 2002).

Although zeolite is used for many purposes, limited data have been published on the use of zeolites on the oxidant/antioxidant status in healthy dairy cows. Yarovan (2008) reported that zeolite has a positive effect on the oxidant status by measuring malondialdehyde (MDA), conjugate dien, keto dien and ceruloplasmin (CP) concentration in the plasma of dairy cows. However, the antioxidant indicator was not analyzed in their study.

Total oxidant status (TOS) and oxidative stress index (OSI) measurement accurately reflect the oxidative status of plasma, because the effects of the oxidants in plasma are

Address for correspondence:

Nurettin Aydilek (PhD)

Department of Physiology

Faculty of Veterinary Medicine

University of Harran

63200 Sanliurfa, Turkey
Tel: +904143183896

Fax: +904143183922

Email: naydilek@hotmail.com

http://www.vfu.cz/acta-vet/actavet.htm 
additive. The total antioxidant status (TAS) is the result of interaction of many different compounds and systemic metabolic interactions. As a single measure, TAS provides relevant information that may effectively describe the dynamic equilibrium between prooxidants and antioxidant in the plasma (Erel 2004). Moreover, TAS could be used as a tool to evaluate the nutritional status of animals fed different diets or to evaluate the general nutritional status of animals throughout the year (Celli 2010).

As for other antioxidant components analyzed in the current study, total free sulphhydryl group (SH) acts as important extracellular scavengers of peroxides, thus helping to protect cells from damage by these molecules ( $\mathrm{Hu}$ et al. 1993). Ceruloplasmin, acute phase protein, acts as antioxidant by several mechanisms (Erel 1998). Paraoxonase (PON) is a high-density lipoprotein-associated enzyme with paraoxonase, arylesterase (ARE), and dyazoxonase activities. Paraoxonase-1 hydrolyzes specific oxidized lipids, thus reducing oxidative stress (Eckerson et al. 1983).

The aim of this study was to investigate the effects of zeolite supplementation in the oxidative/antioxidant status in healthy dairy cows.

\section{Materials and Methods}

Twenty clinically healthy non-pregnant Holstein dairy cows in the first period of lactation (two months after calving), 3-4 years old, were divided into two groups of 10 . Natural zeolite (Nat-Min $9000^{\circledR}$ ) was obtained from Enli Mining Co., Izmir, Turkey. The chemical composition of zeolite containing min $85 \%$ clinoptilolite as active substance is listed in Table 1. Control group was fed basal ration (Table 2) according to the National Research Council (NRC 2001) requirements for lactating cows ad libitum for 60 days. Zeolite supplementation group was fed the basal ration supplemented with $2.5 \%$ zeolite (approximately $400 \mathrm{~g} /$ day). All dairy cows consumed $17.4 \pm$ $0.4 \mathrm{~kg}$ food daily. Water was freely available by automated watering cups. On the $60^{\text {th }}$ day of the experiment the blood samples were collected by jugular vein puncture, plasma samples were separated by centrifugation, and frozen at $-80^{\circ} \mathrm{C}$ until they were analyzed.

Oxidative and antioxidant indicators were measured in plasma samples using the Aeroset automated analyzer (Abbott) and spectrophotometer (Cecil 3000). Lipid hydroperoxide (LOOH) contents were measured with the ferrous ion oxidation-xylenol orange assay (Arab and Steghens 2004).

Total oxidant status was measured using an automated colorimetric measurement method developed by Erel (2005). In this method, oxidants in the plasma sample oxidize the ferrous ion-o-dianisidine complex to ferric ion. The ferric ion builds a colored complex with xylenol orange in an acidic medium. The color intensity was measured spectrophotometrically.

Total antioxidant status was measured according to the method of Erel (2004). In this method, the hydroxyl radical reacts with O-dianisidine to produce a coloured dianisyl radical. Upon the addition of a plasma sample, the reactions initiated by the hydroxyl radical are suppressed by the antioxidant components of the plasma, preventing the colour change.

Oxidative stress index, an indicator of the degree of oxidative stress, was calculated using the following formula: $[(\mathrm{TOS}, \mu \mathrm{mol} / \mathrm{l}) /(\mathrm{TAS},(\mathrm{mmol}$ Trolox Eq/l) $\times 100]$.

Total free sulphhydryl groups of plasma were assayed according

Table 1. Chemical composition of zeolite

\begin{tabular}{lr}
\hline Ingredient & $\%$ \\
\hline $\mathrm{SiO}_{2}$ & 70.9 \\
$\mathrm{Al}_{2} \mathrm{O}_{3}$ & 12.4 \\
$\mathrm{Fe}_{2} \mathrm{O}_{3}$ & 1.21 \\
$\mathrm{~K}_{2} \mathrm{O}$ & 4.46 \\
$\mathrm{MgO}$ & 0.83 \\
$\mathrm{Na}$ & 0.28 \\
$\mathrm{CaO}$ & 2.54 \\
$\mathrm{TiO}$ & 0.089 \\
$\mathrm{MnO}$ & $<0.01$ \\
$\mathrm{P}_{2} \mathrm{O}_{5}$ & 0.02 \\
Others & 7.20 \\
\hline &
\end{tabular}
to the method of Hu et al. (1993). Briefly, plasma and buffer solution was added to a spectrophotometer cuvette followed by the addition of 5,5'-dithio-bis 2-nitrobenzoic acid (DTNB). Samples without DTNB were run for each sample as blanks. Following incubation for $15 \mathrm{~min}$, absorbance was read at $412 \mathrm{~nm}$.

Ceruloplasmin concentrations were measured according to the method of Erel (1998) based on the enzymatic oxidation of ferrous ion to ferric ion.

Paraoxonase-1 and arylesterase activities were measured using paraoxon and phenyalacetate substrates. The rate of paraoxon hydrolysis was measured by monitoring the increase of absorbance at $412 \mathrm{~nm}$ at $37{ }^{\circ} \mathrm{C}$ (Eckerson et al. 1983). Arylesterase activity was analyzed according to the method of Haagen and Brock (1992).

The catalase activity (CAT) was measured according to the method of Aebi (1984).

Statistical analyses were performed using SPSS software, 10.01 (SPSS Inc. Chicago, IL, USA). Data were analyzed using student's $t$-test for independent samples. Results are reported as mean values $\pm \mathrm{SD}$ and differences were considered significant when $P<0.05$. 
Table 2. Composition and calculated analysis of control and zeolite supplemented diets.

\begin{tabular}{lrc}
\hline Ingredients & Control (\%) & $\begin{array}{c}\text { Zeolite } \\
\text { supplementation (\%) }\end{array}$ \\
\hline Wheat straw & 24.04 & 20.69 \\
Alfalfa hay & 26.19 & 26.19 \\
Barley & 10.48 & 10.48 \\
Wheat & 4.19 & 4.19 \\
Maize & 13.10 & 13.62 \\
Cotton seed meal & 5.24 & 5.34 \\
Soybean meal & 10.48 & 10.74 \\
Wheat bran & 5.24 & 5.24 \\
Calcium carbonate & 0.52 & 0.52 \\
Salt & 0.31 & 0.31 \\
Mineral-vitamin premix & 0.21 & 0.21 \\
Zeolite & - & 2.50 \\
\hline Component & & \\
(Analyzed values) & & \\
\hline Dry matter (DM) \% & 90.88 \\
Crude protein \% DM & 18.15 & 18.15 \\
* Metabolic energy (Mcal/kg DM) & 2.35 & 2.34 \\
* Net energy lactation (Mcal/kg DM) & 1.47 & 1.46 \\
Calcium (\% DM) & 0.74 & 0.73 \\
Posphorus (\% DM) & 0.37 & 0.37 \\
Neutral detergent fibre (\% DM) & 38.43 & 35.99 \\
Acid detergent fibre (\% DM) & 24.82 & 23.17 \\
\hline Calculated & \\
\hline
\end{tabular}

*Calculated

\section{Results}

No adverse or side effect was noticed in the cows fed the zeolite supplemented diet throughout the experimental study. Zeolite supplementation resulted in a significant $(P<0.05)$ decrease of $\mathrm{LOOH}$ concentration whereas TOS and OSI values did not decrease (Table 3). On the other hand, no significant changes $(P$ $>0.05$ ) were observed in any antioxidant indicators in plasma (Table 3).

\section{Discussion}

In dairy cows, lactation is a physiological stage considered to induce metabolic stress (Celli 2010). Improvement of the oxidative status of cows can be achieved by modifying nutritional practices (protein, energy, vitamins and minerals). Supplementations of feed additives with antioxidant properties ameliorate the deleterious effects of oxidative stress by scavenging peroxides and reducing lipid peroxidation (LPO). Oxidative stress is characterized by elevated LOOH or ROS concentrations in plasma and tissues. In the current study, LOOH concentration was decreased by zeolite supplementation for 2 months in dairy cows $(P<0.05)$. This result is in agreement with the accumulating evidence that zeolite could play a role as an antioxidant. For example, Yarovan (2008) observed that the MDA concentration decreased after zeolite supplementation in dairy cows. Similarly, Pavelic et al. (2002) reported that LOOH concentration decreased in the liver of cancer bearing mice by zeolite supplementation. This LPO-reducing effect might be associated with adhesion-

*Indicates significantly different $(P<0.05)$ 
adsorption, ion-exchange and cation binding properties of clinoptilolite as well as their saturation with various chemical elements. On the other hand, one of substrates for lipid peroxidation is oxygen. Zeolite reversibly binds small molecules such as oxygen and nitric oxide (Pavelic et al. 2002). Therefore, $\mathrm{LOOH}$ concentration might be decreased due to lower amount of the substrates in tissues at the first step for LPO.

In the present study, TOS and OSI values, indicators of the degree of oxidative stress were not significantly changed $(P>0.05)$. Moreover, the values of antioxidant indicators such as TAS, SH, CP concentrations, PON-1, ARE and CAT activities were not enhanced by zeolite supplementation $(P>0.05)$. These results are in accordance with the results of Stewart et al. (2002) who determined that oxidative stress indicators and oxygen radical absorption capacity were not different between the placebo and antioxidant supplement groups in healthy children. Also, Jacob et al. (2003) reported that moderate antioxidant supplementation did not significantly change in vivo oxidative stress and antioxidant defense system in healthy young men. In other words, when antioxidant capacity of adequate levels is present, the use of additional antioxidant supplementation does not increase the antioxidant capacity in healthy human and animals. However, Ivkovic et al. (2002) indicated that TAS values significantly increased and their general health condition was improved by zeolite supplementation in the patients with a malignant disease. Similarly, clinoptilolite administration inhibited not only oxidative stress but also enhanced the activity of antioxidant enzymes during fluoride-induced neuronal stress on rats (Madhusudhan et al. 2009). In conclusion, in the current study no oxidative and antioxidant indicators except for $\mathrm{LOOH}$ were changed, because the biological antioxidant system in healthy cows was effective; antioxidant supplementation only had an effect when the nutritional status is deficient. Therefore, further studies should be conducted in cows exposed to stress in order to evaluate whether zeolite has antioxidant properties.

\section{References}

Aebi H 1984: Methods in Enzymology. Academic Press, New York, 121 p.

Arab K, Steghens JP 2004: Plasma lipid hydroperoxides measurement by an automated xylenol orange method. Anal Biochem 325: 158-163

Celli P 2010: The role of oxidative stress in small ruminants' health and production. R Bras Zootec 39: 348-363

Eckerson HW, Wyte MC, La Du BN 1983: The human serum paraoxonase/aryesterase polymorphism. Am J Hum Genet 35: 1126-1138

Erel O 1988: Automated measurement of serum ferroxidase activity. Clin Chem 44: 2313-2319

Erel O 2004: A novel automated method to measure total antioxidant response against potent free radical reactions. Clin Biochem 37: 112-119

Erel O 2005: A new automated colorimetric method for measuring total oxidant status. Clin Biochem 38: 1103-1111

Haagen L, Brock A 1992: A new automated method for phenotyping arylesterase (E.C. 3.1.1.2.) based upon inhibition of enzymatic hydrolysis of 4-nitrophenyl acetate by phenyl acetate. Eur J Clin Chem Clim Biochem 30: 391-395

Hu ML, Louie S, Cross CE, Motchnik P, Halliwell B 1993: Antioxidant protection against hydrochlorous acid in human plasma. J Lab Clin Med 121: 257-262

Ivkovic S, Zabcic D 2002: The effect of tribomechanically activated zeolite (TMAZ) on total antioxidant status of healthy individuls and patients with malignant disease. Free Radic Biol Med 33 (Suppl 1): 455

Jacob RA, Aiello GM, Stephensen CB, Blumberg JB, Milbury PE, Wallock LM, Ames BN 2003: Moderate antioxidant supplementation has no effect on biomarkers of oxidant damage in healthy men with low fruit and vegetable intakes. J Nutr 133: 740-743

Karatzia MA, Pourliotis K, Panagiotis DK, Karatzias H 2011: Effects of in-feed inclusion of clinoptilolite on blood serum concentrations of aluminium and inorganic phosphorus and on ruminal $\mathrm{pH}$ and volatile fatty acid concentrations in dairy cows. Biol Trace Elem Res 142: 159-166

Madhusudhan N, Basha PM, Begum S, Ahmed F 2009: Fluoride-induced neuronal oxidative stress and its amelioration by antioxidans in developing rats. Fluoride 42: 179-187

NRC 2001: National Research Council, Nutrient requirements of dairy cattle. National Academy Press, Washington, DC. 
Pavelic K, Katic M, Serko V, Marotti T, Bosnjak B, Balog T, Stojkovic R, Radacic M, Kolic M, Poljak-Blazi M 2002: Immunostimulatory effect of natural clinoptilolite as a possible mechanism of its antimetastatic ability. J Cancer Res Clin Oncol 128: 37-44

Stewart RJ, Askew EW, McDonald CM, Metos J, Jackson WD, Balon TW, Prior RL 2002: Antioxidant status of young children: Response to an antioxidant supplement. J Am Diet Assoc 102: 1652-1657

Vazques-Anon M, Nocek J, Bowman G, Hampton T, Atwell C, Vazquez P, Jenkins T 2008: Effects of feeding a dietary antioxidant in diets with oxidized fat on lactation performance and antioxidant status of the cow. J Dairy Sci 91: 3165-3172

Yarovan NI 2008: Effect of zeolites on adaptation processes in cows. Russian Agricultural Sciences 34: 120 -122 